\title{
The Impact and Application of Mental Capacity Legislation in Care and Family Proceedings
}

\author{
Daniel T Wilcox ${ }^{1,2,3^{*}}$, Marguerite L Donathy ${ }^{1,3}$ and Peter MacDonald ${ }^{1}$ \\ ${ }^{1}$ Wilcox Psychological Associates, University of Birmingham, Birmingham, UK \\ ${ }^{2}$ Centre for Forensic and Family Psychology, School of Medicine, University of Nottingham, UK \\ ${ }^{3}$ Centre for Forensic and Criminological Psychology, University of Birmingham, UK
}

"Corresponding author: Daniel T Wilcox, Wilcox Psychological Associates, University of Birmingham, 55 Raddlebarn Road, Selly Oak, Birmingham, B29 6HQ, UK, Tel: (0044) 121472 0600; E-mail: dwilcox@wpalimited.co.uk

Received date: January 18, 2017; Accepted date: January 31, 2017; Published date: February 03, 2017

Copyright: @ 2017 Wilcox DT, et al. This is an open-access article distributed under the terms of the Creative Commons Attribution License, which permits unrestricted use, distribution, and reproduction in any medium, provided the original author and source are credited.

\begin{abstract}
This paper focuses on the introduction of the mental capacity legislation and in particular its application to care and family proceedings in the UK. It reviews challenges with regards to its implementation, noting serious shortfalls in its use even a decade after the mental capacity act was introduced. Guidance is provided within the paper with regard to maximizing capacity and involvement of individuals in care proceedings where these issues have been raised. Case examples are also used to clarify and to contextualize these matters.
\end{abstract}

Keywords: Mental capacity; Care and family proceedings; Official solicitor

\section{Introduction}

Over the past twelve years, mental capacity legislation has had an increasing, and now global, impact on legal decision making. However, while the associated themes of personal choice and inclusion are laudable, its application in practice has not been without significant challenges. Guidance and training is needed to ensure that this legal directive is consistently adhered to without deviation, however wellintended decisions taken may be.

A decade on, the House of Lords [1] Select Committee on the implementation and application of the Mental Capacity Act (MCA) found that, though marking a turning point in the statutory rights of people who may lack capacity, the Act's implementation has been impeded by poor execution of its basic tenets. Their report states, "The Act has suffered from a lack of awareness and a lack of understanding. For many who are expected to comply with the Act it appears to be an optional add-on, far from being central to their working lives" (p. 6). Their Lordships continue, "The evidence presented to us concerns the health and social care sectors principally. In those sectors the prevailing cultures of paternalism (in health) and risk-aversion (in social care) have prevented the Act from becoming widely known or embedded. The empowering ethos has not been delivered. The rights conferred by the Act have not been widely realized. The duties imposed by the Act are not widely followed" (p. 6). Their Lordships note that the evidence they reviewed in preparing their post-legislative scrutiny of the Act indicated that "thousands, if not tens of thousands, of individuals are being deprived of their liberty without the protection of law, and therefore without the safeguards which Parliament intended. Worse still, far from being used to protect individuals and their rights, they are sometimes used to oppress individuals and to force upon them decisions made by others without reference to the wishes and feelings of the person concerned" (p. 7).
Worryingly, a lack of adherence to the MCA [2] and its principles is cited as a contributing factor to premature deaths of adults with learning disabilities, associated with 'best interests' 3 decision making processes and a lack of clear understanding of the definition of 'serious medical treatment', under the provisions of the Act [3]. Other studies and reports, including the Confidential Inquiry into Premature Deaths of People with Learning Disabilities (CIPOLD) have come to similar conclusions. CIPOLD [4] reviewed the deaths of 247 people with learning disabilities in England and Wales between 2010-2013 in response to the Mencap [5] report, 'Death by Indifference'. The inquiry reported that reviews of the deaths of people with learning disabilities identified concerns about adherence to the Mental Capacity Act, and the differences in the understanding and implementation of each of its principles. There was evidence of disagreement as to what professionals understood concerning decision making about medical intervention and thus a lack of consistency about appointing Independent Mental Capacity Advocates to support those without family members to represent their views. The Mental Capacity Act has now had more than 10 years to find its place in English and Welsh law, and there are a range of resources available to professionals to support its implementation. However clearly more needs to be done in this regard [4]. The present authors will explore mental capacity assessment in some detail from a UK perspective focusing on its application in care and family proceedings. However, mental capacity legislation has much broader application across the entire social engagement and individual decision making spectrum [6,7]. As such, we will first set out the historical antecedents and outline the range of uses of mental capacity assessments in order to provide a better understanding of its employment in care proceedings.

\section{Historical Underpinnings}

Maureen Piggot, Inclusion Europe's first President, stated, "The right to make your own decisions and to be in control of your own destiny is a right that we all take for granted. Even with the common-law presumption of capacity, people with a learning or intellectual disability are often asked to prove their capacity before being allowed 
Page 2 of 7

to make routine everyday decisions, as well as decisions that are significant and serious in their life such as where they live and with whom, for example" [8]. Historically, laws concerning individual choice and the retention of decision making powers generally related to circumstances where it was deemed appropriate to withhold or deny these rights even to the point of restricting personal liberty. These decisions were most often entwined with the issue of assessing the individual's mental health. It may be noted that in England and Wales legislation has, over a period of two centuries, gradually progressed towards more humane and enlightened handling of these matters. Meanwood Park Hospital in Leeds, England has a website entitled 'The Evolution of Mental Health Law' wherein they provide "a timeline history of the Acts of Parliament affecting the evolution of mental health" laws. For purposes of producing this paper a brief listing of the most relevant legislation gives the reader a sense of this journey with the passage of the Madhouse Act [9], the Lunacy Act [10], the Mental Deficiency Act [11], the Mental Treatment Act [12], the National Health Service Act [13] and the Mental Health Act [14,15].

Notably, the transition towards maximizing the exercise of individual choice and more objectively, assessing the need to restrict rights finally manifested itself more fully with the passage of the Mental Capacity Act [2]. This legislation highlights important relational features that exist between mental health and capacity issues such that choices determined appropriate can, for example, be made by even compulsorily hospitalised individuals where they are assessed to have capacity to put specific views forward. The MCA's principal aim is to protect and empower individuals who may, without this mandate, be assessed as not having capacity.

In the interest of safeguarding individuals as well as society, an interplay often exists between mental health and mental capacity legislation with an increasing emphasis on the legal requirement for decisions that are made to be issue specific and ensure that individuals are afforded the opportunity to make their own choices wherever they are considered mentally competent to do so. It establishes safeguards to empower and protect individuals whose assessed mental capacity is in question by providing a framework for systematically assessing and reassessing such matters. Mental capacity legislation in England and Wales sets out to clarify legal uncertainty and maximise the right of choice among its citizens. Importantly, the MCA requires that 'decision specific tests' are set out for assessing capacity in the various areas of enquiry. These decisions may relate to financial matters, health concerns, welfare, substitute decision making and appointment of other parties. The MCA includes new rules to govern research involving people who lack capacity as well as the provision of new 'Mental Capacity Advocates' to represent and support any such individuals, where deemed appropriate. The MCA provides recourse to the court where necessary and has brought forward a new Court of Protection which has more comprehensive powers to safeguard individuals whose mental capacity may be brought into question.

\section{People Impacted upon by Mental Capacity Legislation}

The MCA [2] affects people who are sixteen years or older and living in England or Wales. The people most commonly affected by mental capacity legislation are those affected by dementia [16], learning and/or physical disabilities [17], mental ill health [18], or an acquired brain injury [19]. Mental incapacity may be temporary as with individuals affected by substance intoxication, treatable delusional beliefs, transient conditions that impact on psychological wellbeing, or difficulties as normal as childbirth, wherein an agreed post-delivery time must elapse before normal mental capacity is said to resume [20].

\section{Defining Features of the Mental Capacity Act}

The MCA [2] has a number of inherent principles to enable and maximise choice. For example, decision makers are directed to begin any processes to determine capacity working with the premise that everyone can make their own decisions. Further, a key component of the MCA is a mandated acceptance that no-one should be stopped from making a choice simply because their decision may be thought by others to be unwise, eccentric or not clearly in their best interests i.e., an individual considered to have capacity to make their own decisions is perfectly entitled to make 'bad decisions', as judged by others. However, a challenging caveat of the Act is the requirement that anything done for or on behalf of a person lacking capacity must be determined to be in their 'best interests. Clearly, such a decision may not be consistent with the above wherein an individual deemed to have capacity may volitionally choose to make a decision that others may regard as unwise. Nevertheless, when choices must be made that are judged to be in the 'best interests' of an individual, the MCA [2] makes clear that decisions should be arrived at by working through a checklist considered 'fit for purpose' in the specific circumstances and engaging the individual in this process as fully as is deemed appropriate and safe. A further key principle of the MCA [2] makes clear that whenever a decision is made or an action is undertaken for a person who is considered to lack capacity concerning a particular issue, the decision must advance the least restrictive options in relation to the individual's basic rights and range of choices.

\section{Mental Capacity Assessment}

The MCA [2] requires that a two-stage test of capacity is undertaken [21]. Specifically, the following questions must be asked: Is there an impairment or a disturbance in the functioning of the person's mind or brain?; if so, is the impairment or disturbance such that the person lacks capacity to make decisions in relation to the issues at hand, for example conducting care proceedings? The specificity of the issue in question is of primary importance and should involve a careful review of whether the lack of capacity is temporary, does the person have the capacity to make other related decisions, or does the person's capacity fluctuate in a way that makes independent decision making by them unsafe. It is also noted that the individual may have the ability to conduct some aspects of the proceedings but, for example, not be able to make decisions in relation to broad or narrow issues under discussion. Bearing this in mind, a person may be given a certificate of incapacity in relation to various aspects of proceedings. The certificate indicates whether the individual is capable or lacks capacity within the meaning of MCA [2] of conducting specified aspects of the proceedings. A decision of incapacity may be taken where an individual suffers from impairment of, or disturbance in, the functioning of the mind or brain and is unable to understand relevant information, unable to retain that information, unable to use or weigh up the information as part of the process of making decisions in the conduct of the proceedings, and find a way to effectively convey these views to their solicitor and the court. In some situations, the possibility of regaining or developing capacity to conduct the proceedings may justifiably lead to a delay in the legal process until such capacity is achieved.

In order to assess capacity, practitioners often utilise a range of psychometric measures focusing upon cognitive functioning, 
personality assessment, affective presentation, insight and judgement. Capacity assessment may incorporate an evaluation of cognitive functioning employing, for example, the Wechsler Adult Intelligence Scale-Fourth Edition (WAIS-IV). The WAIS-IV [22] is the latest version of the Wechsler Adult Intelligence Scale and is an individually administered clinical instrument suitable for examinees aged between sixteen and ninety. It provides composite scores that reflect intellectual functioning in specified cognitive areas, as well as a composite score that represents general intellectual ability (i.e. Full Scale IQ). The WAIS-IV also yields a General Ability Index, which is less sensitive to the influence of working memory and processing speed. Of course, intellectual ability does not determine capacity. However, it can offer insights into the various areas being assessed, namely, verbal comprehension, perceptual reasoning, working memory processing speed. These various areas can contribute to an understanding of the individual's comprehension, their ability to retain information, to weigh up consequences and to communicate their decisions. However, clinical interviews are the most critical aspect of the assessment, taking time to explore with the client their understanding of the Court process and the role of the various parties.

Besides being able to discuss proceedings with their legal representatives, a decision must be made as to whether any detrimental effect from such discussion may befall the individual further to contributing, within the process of determining their views in relation to the proceedings, and adequately protecting the individual throughout this process. Notably, the Official Solicitor (OS) or 'Litigation Friend' plays an important role where individuals lack capacity. This legal entity has been in existence for over 100 years. In the UK, the Official Solicitor of the Supreme Court is appointed by the Lord Chancellor and exists as 'an arm's length body' of the Ministry of Justice. The OS acts for people who lack mental capacity, cannot properly manage their affairs, and are unable to represent themselves and identify another person or agency that is able or willing to act on their behalf. The OS acts for the Ministry of Justice in England and Wales in relation to children, adults and the deceased where capacity issues are considered to be of key litigation importance.

\section{Capacity Legislation Considered from a Broader Perspective}

Article 12 of the United Nations' Convention on the Rights of Persons with Disabilities (CRPD) established "a Landmark Treaty" adopted by the UN General Assembly in 2006 and to which the UK is a signatory. It was the first legally binding UN convention protecting and promoting the rights of people with disabilities including those with psycho-social disabilities (mental health problems) or mental disabilities. Since its introduction to the UN in 2007 there have been eighty-two signatories to Article 12 of the CRPD. Further, having been negotiated during eight sessions of an ad-hoc committee of the General Assembly between 2002 and 2006 the CRPD became the fastest negotiated Human Rights Treaty in the UN's history.

The UK is also signatory to the European Convention of Human Rights, 1953. The European Convention for the Protection of Adults [23] has been ratified in part of the UK, though only in Scotland. However, the authors note that Schedule 3 to the Mental Capacity Act [2] gives effect to the Convention in England and Wales insofar as the MCA does not otherwise do so and makes related provision as to the private international law of England and Wales.
The creation and implementation of mental capacity legislation in other jurisdictions has not proceeded without hiccups. Prior to the recent Assisted Decision Making (Capacity) Act [24] in Ireland, the Irish government relied upon legislation dating to the later $19^{\text {th }}$ century-the Regulation of Lunacy (Ireland) Act [10]. As such, Ireland was prevented from ratifying the UN convention on the Rights of People with Disabilities. Colm O'Gorman, Executive Director of Amnesty International, Ireland, reported in 2012, "Ireland is behind every other European country in this area. While other countries allow for people to be supported making decisions Ireland takes all rights away from the person and the court imposes the decision on them". Continuing, he noted, "it is simply unacceptable that we are relying on legislation that is more than 140 years old to make capacity decisions in Ireland" [8]. After half a dozen years rumbling through the Irish parliament, the Assisted Decision Making (Capacity) Act was finally passed in 2013, providing Ireland with capacity law which empowers the individual to maximise their ability to make independent decisions. Commenting on this, Professor Gerard Quinn, Director of the NUI Galway's Centre for Disability Law and Policy, described, "Internationally, there is a move away from guardianship systems that nearly always end on trampling on people's autonomy towards regimes that support people making decisions for themselves. This bill should restore legal capacity to persons with disabilities". Continuing, Prof Quinn reported, "at the end of the day this should be about expanding the civil rights of a person...it's a once in a generation chance to get this right". Notably, unlike England and Wales where no single body has responsibility for the implementation of the Mental Capacity Cat, the Irish Assistant Decision Making (Capacity) Act [24] provided for an Office of the Public Guardian. Though the United Kingdom has a statutory body of the same name, the British Public Guardian's remit is significantly narrower than the Irish Public Guardian insofar as the UK Office of the Public Guardian primarily deals with regulating those exercising powers of attorney. By contrast, the Irish Public Guardian is tasked with "the promotion of public awareness of matters including the principles and procedures of the United Nations Convention of the Rights of Persons with Disabilities".

Internationally, there remain scores of governments that continue to 'turn their heads' in relation to introducing responsive mental capacity legislation [25]. However, there appears to be a growing movement towards safeguarding and empowering individuals offering them the maximum possible choice in personal decision making that is considered within their rights and competency to assume.

\section{Assessing Capacity for Care and Family Proceedings}

Over time, capacity assessment has increasingly become issue specific with the assessment of capacity becoming focused on decision questioning and evaluation. Particular areas of enquiry might include questioning; for example, does an individual have capacity to consent to adoption? Can they manage specified financial matters, make a will, give a gift, litigate, enter into a contract, vote or make choices within the context of relationship decisions? Capacity decisions can have a significant influence on individuals in various legal situations, such as addressing questions within criminal proceedings, engaging in clinical procedures or research as well as making choices that could deprive the individual of their liberty. Importantly, where all individuals lack capacity, fair, responsible, and person-centred representation should be provided with the aim of supporting the individual's best interests as well as taking account of their wishes. 
A helpful practical guide to the assessment of mental capacity for medical and legal professionals is provided by Letts [26]. This is a third, revised, edition which details the steps that are generally advised to be followed by clinicians undertaking mental capacity assessments within the context of legal proceedings. However, the full guidance is beyond the scope of the present article, though covered more extensively by the author in other contexts [25,27], and within a wide range of other postgraduate professional clinical or forensic training programmes in psychology, psychiatry, social work, etc. Nevertheless, the systematic assessment of capacity incorporates two broad aims; firstly, accurately assessing the individual in relation to their capacity for making the decision in question and secondly, enhancing mental capacity to maximise the individual's ability to make their own decisions.

A thorough assessment of capacity requires a comprehensive review of all available relevant background and historical information including medical records and reports. Such assessments will necessitate interviews with the individual to determine their ability to coherently provide self-reports about them and to gain clinical information concerning their cognitive abilities, memory and communication skills. A mental status examination should be carried out in addition to a structured personal history interview and general observations made about the individual's appearance and behaviour throughout. The mental status evaluation assesses mood factors, thought processes, memory, perception, insight, judgement, orientation to person, place and time, as well as reality testing abilities. All of these clinical factors can impact upon mental capacity and, psychometric measures are also often employed, to assist, in particular, where formal cognitive assessment is considered to be warranted. Further, more specialised measures may be used to assess relevant neurological features, for example, memory and executive functioning abilities like abstraction, cognitive organisation, etc.

\section{Improving Capacity}

However, it is important for the assessor to incorporate a 'functional' approach in terms of assessing the client's abilities, behaviours or capacities to determine what the individual understands, knows, believes and can demonstrate, that is directly relevant in the legal context at issue. Specifically, the clinician should focus on identifying the extent to which these functional abilities meet the demands of a particular situation within a given legal context, for example, what aspect of legal proceedings can the individual meaningfully contribute to and what aspects may lay outside of their range of abilities. The clinician should also endeavour to identify ways to enhance the individual's capacity (and this may be in collaboration with other professionals) to assist the individual in maximally contributing to decision making. The ways of achieving this are likely to be varied and may be quite idiosyncratic in accordance with the individual's specific needs, circumstances and abilities. This may, for example, involve decisions concerning the treatment of a medical condition where current incapacity is in evidence but may be temporary, as in some cases with memory loss, mental health instability or significant episodes of substance intoxication/withdrawal that might, for a time limited period, reduce capacity below a level safe for independent decision making.

Notably, specialized training for individuals lacking capacity may also be of assistance. For example, steps may be taken to address short term memory deficits, through employment of written materials, pictorial representations and other aids that could be tailored to assist the individual to sufficiently understand and retain information in a way that allows them to weigh up the relevant matters and, responsibly (independently or with assistance) arrive at a decision. It may be that the individual has difficulties concentrating for long periods of time and that scheduled breaks in the legal process improve the individual's capacity. Further, sensory motor challenges may interfere with the individual's capacity for communicating effectively though with diligence, even with extreme conditions, like 'Locked-In syndrome' where the sufferer is affected by a neurological disorder that completely paralyses their voluntary muscles with the exception of them being able to volitionally move their eyes and eyelids [28], this can be achieved. Therefore, with patience and in some situations the use of assistive technology, such individuals can be helped to communicate their views and demonstrate mental capacity in relation to relevant legal issues.

Additional factors to be taken into account in both assessing and enhancing capacity within legal proceedings may include the location and time of appointments as well as their duration. Concerted efforts should be taken to optimise the individual's ability to interact effectively. Further efforts should be made to identify all relevant factors impacting on capacity during the assessment and included in the capacity report to inform the Court as to how meaningful participation can be maximized. At times, focal educational efforts can be helpfully applied, in particular, where they have relevance to enhancing the individual's learning and retention capacity, and with this, their ability to engage more fully within the context of the specific legal proceedings. In some circumstances, capacity may also be improved by the presence of a friend or relative, although a third party might, in other situations, increase anxiety. This may particularly be the case where the third party has different aims and objectives than the individual whose capacity is being assessed within the proceedings. Indeed, Whitman and Accardo [29] have noted that in some individuals with intellectual limitations there is a tendency for them to have existed in an environment wherein they frequently rely on the support of others to obtain goods and services usually determined by those around them for example careers and family members. Whitman and Accardo referred to this as the 'Cloak of dependency'. Thus, where professionals are endeavouring to facilitate capacity, difficulties are likely to be experienced when attempting to engage with those members of society who have likely become accustomed to deferring to others, even though it may relate to choices about their own life and about which they are capable of making their own decisions.

\section{Employment of the Official Solicitor}

When mental capacity is viewed as inadequate, it becomes necessary to consider the involvement of the Official Solicitor (OS) who will, in the absence of any other willing and suitable party, act on behalf of the client and take all appropriate steps to safeguard the client's best interests [21]. However, clinically based evidence is required before the OS can consent to act. When acting for a parent the OS is under a duty to garner all relevant evidence to be enabled to reach a balanced view of the merits of the case of the incapacitated client and likely outcome. The OS may assist by representing the individual in respect of a range of matters including placement or adoption issues, residence or contact disputes, resolution of parentage matters and even issues such as family law injunctions. The OS is only retained in circumstances where it has been determined that the individual involved lacks capacity in respect of undertaking and delineating issues considered to be of direct relevance to the legal matters at hand. 
In Care and Family proceedings the involvement of the OS usually occurs through a party's existing solicitor seeking a Court Direction that the OS be invited to act as Litigation Friend, supported with the standard OS certificate generally completed by the psychologist, psychiatrist or other clinician instructed to undertake the capacity assessment. The OS must agree to the invitation to act and cannot be ordered to do so. If the OS does, it is their responsibility to either provide instructions to the existing solicitor, or instruct another if it is thought the existing solicitor lacks the required experience. In every case the solicitor must now include their clients' wishes for their children in the statement submitted to court, although ultimately it is the OS who will provide instructions about how the case should be run on behalf of a parent or parents who lack capacity. In recent years, since the introduction of the MCA (2005) legislation, a notably more robust approach has been taken by the OS, in challenging Care Plans.

\section{Case Examples}

The authors have reviewed cases in order to provide relevant examples to assist the reader in better understanding the complexities of Mental Capacity Act (2005) and its application in care proceedings. The examples describe relevant challenges to the responsible employment of the Mental Capacity Act within legal and clinical settings. The cases have been fabricated but reflect realistic examples of the kind of issues that the authors encounter in this field of work.

A young woman, Ms $\mathrm{R}$, was assessed in respect of proceedings concerning her infant daughter, $\mathrm{K}$, who had been placed into Local Authority care following birth. Ms $\mathrm{R}$ was deemed a vulnerable female with cognitive limitations, who had experienced a chaotic and traumatic upbringing. By the age of eighteen, Ms R was involved in a relationship and became pregnant with $\mathrm{K}$. As a result of concerns regarding Ms R's vulnerability and the couple's poor living conditions, a pre-birth parenting assessment was undertaken. Ms R's attendance at these sessions was sporadic and her knowledge of child rearing proved to be both poor and not readily responsive to the training offered.

Following the birth of $\mathrm{K}$, the couple's parenting skills and attachment were monitored during supervised contact. Given continued concerns about the parents' inability to provide adequate care, the Local Authority made an application for Care and Placement Orders, considering that adoption was the most appropriate plan for the child. In preparation, Ms R was asked about her understanding of such a placement. During structured psychological assessment of this issue, Ms $\mathrm{R}$ was unable to grasp the difference between fostering and adoption even after sustained efforts were made to explain these matters to her. In the circumstances, the OS was requested to act on behalf of Ms R and it was judged that she did not have the capacity to give consent. (However, her partner did not require such support or assistance, though he was not considered to be appropriately placed to act on her behalf).

In another case example, a woman, Ms. G, had previously been assessed by one of the authors in respect of her cognitive abilities and it was found that she had a significant diagnosed Intellectual Disability [30]. A further assessment request was subsequently made for Ms G to be evaluated in respect of her capacity for consenting to the proposed adoption of her nineteen month old son. During the appointment, Ms. G's understanding about this process was systematically reviewed. Ms. $G$ demonstrated sufficient understanding of the role of the Judge noting "he decides where it is best for the baby to go" and of her solicitor stating "he fights for me and talks to the Judge", while description of the barristers' roles reflected adequate though perhaps rather superficial understanding. Ms $G$ recognised that her son had a "Guardian" (Ad Litem), who was also represented. Ms G further reported that witnesses in the case "give information and have to tell the truth".

When the discussion turned to her son, Ms. G was asked what could happen to him in the context of the current Child Care Proceedings. Ms $G$ indicated that her son could be returned to her care, or an extended family member. Ms G considered that this latter option would not likely be pursued for safety reasons, in part associated with the initiation of Care Proceedings involving this 'potential carer' eighteen months previously. As such, Ms G considered that placement outside of the biological family was preferable at that time and she expressed the view that fostering, rather than adoption, would be best, offering her the opportunity of maintaining direct contact with her son. When this was explored further, Ms G indicated that if her son remained in foster care then she could potentially continue having supervised contact with him, whereas if he was adopted she would only be "allowed to send letters and cards for his birthday". Ms. G also explained that if her son was adopted, he would have a "new mommy and daddy". While discussing this, Ms. G became tearful and indicated that although she wanted her son returned to her care, she admitted that for his sake he would have a better life if he was adopted than in long term foster care.

The assessment of Ms G concluded that not only had she comprehended and 'weighed up' the relevant legal issue, she had retained the salient points and communicated her decision that although she did not want her son adopted, she adequately understood the implication of such a decision. In our opinion, this was a good example of a situation where some of the parties appeared to have formed a preliminary view that Ms G likely lacked capacity in relation to these proceedings on the basis of her previously assessed global cognitive delays. However, in relation to the key issue of adoption it was judged that she did have capacity.

In a further case, $\mathrm{Mr}$. $\mathrm{M}$ had undergone a cognitive assessment and following on, questions had been raised about his capacity for providing instruction to his solicitors in respect of Care Proceedings involving his son. Mr. M's performance on the WAIS-IV [22] was reflective of functioning within the Extremely Low range and indicative of a Mild Intellectual Disability [30]. Mr. M had also attended special schools during childhood and an assessment of his current adaptive functioning evidenced significant impairments. In this case, it was considered that the OS should be invited to act as Mr. M's Litigation Friend owing to his assessed significant cognitive difficulties and related comprehensive lack of understanding of the conductance of the proceedings.

Subsequently, and as a result of the Local Authority's intention to place his son for adoption, a request was made for a further more specific assessment of Mr. M's capacity to consent to such action. During a further appointment, wherein pictorial aids were used, Mr. M demonstrated an adequate understanding of adoption and, articulating his opinions in respect of the Local Authority's plan; he vehemently opposed adoption and indicated that he wanted to "fight" to keep his son in his life. The Court was advised that Mr. M had capacity to give consent to the adoption of his child, though it was recommended by the (capacity) assessor that the same pictorial aids employed during the psychological assessment should be used when Mr. M attended Court to assist him in retaining the relevant information about which he was capable of consistently giving an opinion. 
In the final case example, Ms. D suffered from a severe bipolar disorder [30] such that she was highly dysregulated and irresponsible in her behaviour over the course of a year following the birth of her son. During this time she was judged to lack capacity to consent to care proceedings, though at the time we assessed Ms D, she had achieved a considerable amount of stability and had become involved in a further and apparently more secure relationship. During our assessment, we considered that, at the outset, her mental capacity continued to be variable with transient periods of significant psychological confusion and distress that severely reduced her mental capacity. However, over the course of the assessment the situation improved. Further, her ability to understand the nature of the Child Care Proceedings that she was involved in and consider various issues and alternatives in a rational way increased to the point that it was judged that she would no longer require the assistance of the OS. As such, over the course of the proceedings, it became possible to engage Ms. D in these proceedings in a fully participative way with conventional legal representation.

\section{Conclusions}

Assessing whether an individual has mental capacity can be complex and challenging. The Mental Capacity Act [2] provides the legal framework for addressing this aim and this is supported by a Code of Practice [31] that provides helpful guidance about how the Act can be applied in practice. Notably, within medical-legal decision making, there is a requirement for professionals to have demonstrated that they have fully considered such relevant advice to ensure that issues concerning mental capacity are addressed in a systematic and responsible manner. The Act is intended to empower and protect an individual's rights to make decisions for them and provide a structure for proper assessment when this issue is in question. Decisions covered by the Act are diverse and can range from relatively mundane matters to significant life changing issues but the underlying principle of 'assumed capacity' which holds throughout the Act, makes it clear that a person must not be treated as unable to make a decisions unless all possible efforts have been taken without success.

In February 2010, the Mental Health Foundation [32] launched a free online Assessment of Mental Capacity Audit Tool (AMCAT). This was designed to assist individuals working within health and social care settings to audit and evaluate mental capacity assessments about which they have direct involvement. The report, produced on the basis of initial data gathered, gives an indication of how well the completed mental capacity assessments complied with the tenets of the Mental Capacity Act (and the associated Code of Practice). After a period of employing this tool for three to four months, initial analysis was undertaken revealing that less than ten percent $(10 \%)$ of those who had completed the AMCAT were following the Code of Practice adequately. The concerns noted included many fundamental errors. The study revealed that thirty eight percent $(38 \%)$ of the respondents had not adhered to the Act and that their basis for conducting a mental capacity assessment was owing to concerns unrelated to specific doubts about capacity. Rather, the evaluations were associated with issues such as the age of the individual or matters including their appearance, history, diagnosis, illness or reported behavioural anomalies. This is concerning in that the central aim of the Act is to assess capacity on a decision-specific basis. This serves to avoid the kinds of errors that can too readily occur with offering blanket opinions based on an individual's general presentation as opposed to targeted judgements relating specifically to an individual's understanding, retention, comprehension and communication skills concerning a clearly delineated, operationally defined matter. It was further noted that twenty four percent (24\%) of the mental capacity assessments within this study appeared to relate to a perception of poorly judged decision making rather than a consideration of the aforementioned requirements to establish mental capacity. It is disturbing that nearly one quarter of these assessments were initiated because an individual chose to make a decision considered by others to be unwise. One might recall the famous quote of George Best, when he described having "spent a lot of money on booze, birds and fast cars" whilst reporting that he had "just squandered" the rest (http:// www.quotationspage.com/quote/31947.html). On reflection, it may appropriately be questioned whether a lower profile individual in similar circumstances, might have been subject to a mental capacity assessment and in spite of having the ability to consider the consequences of the various alternative courses of action they might take, to be deprived of the opportunity to 'choose' the one they want, because it met with the disapproval of significant others.

Unrestrained, good intentions are not the aim of the Mental Capacity Act [2], while empowerment and adequately informed personal choice is its purpose. The protection from harm, of individuals who lack capacity, in relation to specific issues, is a key concern of this legislation, as well as maximising personal decision making opportunities (even where poor judgement, impulsivity or unusual levels of sensation seeking may be the order of the day). The Mental Capacity Act is intended to safeguard and aid individuals in pursuit of their aims and not hinder them from making personal choices in conducting their affairs. In spite of noted shortcomings in the implementation of the Mental Capacity Act the use of this framework for more accurate and responsive assessment has progressed and it increasingly offers a potential for better legal decision making. Within the specific area of Care Proceedings the Mental Capacity Act [2] has led to greater protection and participation for some of the most vulnerable parents and carers in our society. Accordingly, this important legislation has served to inform and assist the legal process to better empower vulnerable parents in making a fuller and more meaningful contribution to Care and Family Proceedings concerning their children.

\section{Acknowledgements}

The authors would like to thank Zerine O'Keeffe, Fiona LawsonHughes, Jane Swancott and Nicole Horton for their advice and assistance in preparing this paper.

\section{References}

1. Mental Capacity Act: Post Legislative Scrutiny (2014).

2. http://www.legislation.gov.uk/ukpga/2005/9/pdfs/ ukpga_20050009_en.pdf

3. Heslop P, Blair PS, Fleming P, Hoghton M, Marriot A, et al. (2014) The confidential inquiry into premature deaths of people with intellectual disabilities in the UK: a population-based study. Lancet 383: 889-895.

4. Confidential Inquiry into the Premature Deaths of Adults with Learning Disabilities (2013).

5. Mencap (2012) Death by indifference: 74 deaths and counting. A progress report 5 years on.

6. Lennard C (2016) Fluctuating capacity and impulsiveness in acquired brain injury: the dilemma of "unwise" decisions under the Mental Capacity Act. The Journal of Adult Protection. 18: 229-239. 
Citation: Wilcox DT, Donathy ML, MacDonald P (2017) The Impact and Application of Mental Capacity Legislation in Care and Family Proceedings. J Foren Psy 2: 117. doi:10.4172/2475-319X.1000117

Page 7 of 7

7. Spencer-Lane T (2015) Mental capacity and deprivation of liberty: the Law Commission's consultation paper. The Journal of Adult Protection 17: 331-334

8. Inclusion Ireland National Association for People with an Intellectual Disability (2012). Learning Disability roundtable: 'An Opportunity to turn rights into reality.

9. Madhouses Act (1774).

10. http://www.irishstatutebook.ie/eli/1871/act/22/enacted/en/print.html.

11. https://en.wikipedia.org/wiki/Mental_Deficiency_Act_1913.

12. https://en.wikipedia.org/wiki/Mental_Treatment_Act_1930.

13. http://www.legislation.gov.uk/ukpga/1946/81/pdfs/ ukpga_19460081_en.pdf.

14. http://www.legislation.gov.uk/ukpga/1983/20/contents.

15. http://www.legislation.gov.uk/ukpga/2007/12/pdfs/ ukpga_20070012_en.pdf.

16. Regnard C, Louw S (2011) Embedding the Mental Capacity Act into clinical practice in England and Wales. Age and Ageing 40: 416-418.

17. Cowley J, Lee S (2011) Safeguarding people's rights under the Mental Capacity Act. Nursing Older People 23: 19-23.

18. Wilson S, Dhar R (2010) Consent to treatment, the Mental Health Act, and the Mental Capacity Act. Psychiatry in Prisons: A Comprehensive Handbook. London, Jessica Kingsley Publishers, England, pp: 144-154.

19. Mukherjee D, McDonough C (2006) Clinician perspectives on decisionmaking capacity after acquired brain injury. Topics in Stroke Rehabilitation 13: 75-83.

20. Antenatal and postnatal mental health (2007)NICE clinical guidance 45, National Collaborating Centre for Mental Health, British Psychological Society, UK.
21. Keene AR (2015) Assessment of mental capacity: A practical guide for doctors and lawyers. London, Law Society Publishing, UK.

22. Wechsler D (2008) Wechsler Adult Intelligence Scale. (4th edn) Psychological Corporation.

23. The Hague Convention on the International Protection of Adults (2000).

24. http://www.oireachtas.ie/documents/bills28/bills/2013/8313/b8313d.Pdf.

25. Wilcox DT, O'Keeffe ZC, Lawson-Hughes F (2013) The Application of the Mental Capacity Act in Care and Family Proceedings. Symposium for The European Association of Psychology and Law. Coventry University, Coventry.

26. Letts J (2010) Assessment of Mental Capacity: A Practical Guide for Doctors and Lawyers.

27. Wilcox DT, O'Keeffe ZC (2010) Mental Capacity and Fitness to Plead. Presentation for the University of Birmingham Forensic Psychology Postgraduate Programme (Spring).

28. https://www.ninds.nih.gov/Disorders/all-disorders.

29. Whitman BY, Accardo PJ (1990) When a parent is mentally retarded. Baltimore, MD: Paul H. Brookes.

30. American Psychiatric Association (2013) Diagnostic and Statistical Manual of Mental Disorders (5th edn.). Arlington, VA: American Psychiatric Publishing, USA.

31. Department of Constitutional Affairs (2007) Mental Capacity Act 2005. Code of Practice.

32. Mental Health Foundation (2010) Mental Capacity assessments: working in practice? Initial findings from the mental health Foundation's Assessment of Mental Capacity Audit Tool (AMCAT). 